\title{
Classifying logistics-relevant disasters: conceptual model and empirical illustration
}

\begin{abstract}
Purpose

This paper intends (1) to use a theory-based approach to develop a new classification model for disasters that reflects their logistics implications, and (2) to contextualise the findings by applying the model to a particular disaster situation.
\end{abstract}

\section{Design/methodology/approach}

A widespread literature review was conducted in order to conceptualise the proposed disaster classification model and a case study (the 2011-2012 Somali food crisis) was used to provide a practical illustration and an initial validation of the conceptual approach.

\section{Findings}

The new classification model proposes a set of four categories of disasters based on two generic dimensions, whilst simultaneously integrating five situational factors that reflect the impact of the external environment on the logistics operations. The case study confirms that this systemic approach is necessary since, from a logistics perspective, a disaster should be considered in its entirety and within its contextual environment.

Research limitations/implications

Further research is needed to establish the operational characteristics of each disaster type in order to determine the applicability of business logistics practices to each scenario. In addition, this paper highlights the opportunity to validate or refine the model by using a more varied range of case studies.

Originality/value

This paper proposes a new classification model for disasters based on their logistics implications and, by integrating the key environmental factors, it moves beyond the traditional 2x2 model found in the literature.

\section{Keywords}

Humanitarian logistics; Disaster classification; Typology building; Open systems; Generic characteristics; External environment

Article classification

Conceptual paper

\section{Introduction}

A disaster is defined by the United Nations (UN) as 'a serious disruption of the functioning of a community or a society involving widespread human, material, economic or environmental losses and impacts, which exceeds the ability of the affected community or society to cope using its own resources' (UNISDR, 2007). This definition reflects huge variety in the implications and response conditions of a disaster and this, inevitably, creates significant difficulties for the researcher. As a way of attempting to rationalise this potentially confusing picture, a number of disaster classifications have been developed within the disaster management literature (see Shaluf, 2007; Eshghi and Larson, 2008). However, none of the existing classifications explicitly reflects the logistics implications of such events (L'Hermitte et al., 2013). Since disasters generate diverse operational environments (and, hence, logistics responses), it is important to differentiate between disaster categories in order to develop appropriate analyses and consequential recommendations that will enhance the efficiency and/or effectiveness of the logistics operations (Holguín-Veras et al., 2012). 
The objectives of this paper are two-fold: (1) to propose a new classification model for disasters that reflects their logistics implications and (2) to contextualise the findings by applying the model to a particular disaster event. To this end, the next section describes the methodology used in this research. This is followed by a section which presents the conceptual framework (based on typology building and the concept of open systems). In the subsequent section, the limitations of the typology commonly used in the humanitarian logistics literature are addressed, before the new disaster classification model is presented. A case study analysis of the proposed model based on the 20112012 Somali food crisis is provided in the next section. Following this, the value and conclusions of this work are summarised and its limitations are identified. The final section synthesises the research.

\section{Methodology: literature review and case study}

The development of the new classification model is based on a widespread review of the literature in various academic fields. First, the literature relating to the construction of typologies and the general system theory (in particular the model of open systems) was used to develop the conceptual framework of this paper and to provide an overview of the optimal approach for developing the two-level classification framework. This review is designed to be complementary to L'Hermitte et al. (2013) who consider the academic literature in the social science of disasters. In addition, this approach is similar to the one chosen by Pettit and Beresford (2009) who draw on another academic discipline and identify the relevant aspects to the field of humanitarian logistics. To that end, and in line with the work of Kunz and Reiner (2012), we searched the ProQuest, Business Source Premier, and Scopus databases, as well as Google Scholar using the following keywords:

- "General system theory" or "general systems theory" or "open system" or "open systems"

- "Typology" or "typologies" or "Typological" or "Taxonomy" or "Taxonomies" or "Classification" or "classifications".

Citations from relevant articles were also used to expand the research. The results were, then, considered alongside the HUMLOG bibliography developed by Peter Tatham (HUMLOG, 2014). The overall aim was to understand the limitations of the commonly used typology based on the nature of disasters and the speed of onset, as well as to identify the emergent discussions regarding alternative classifications.

In addition to the literature review, a case study is used to illustrate the proposed model in a real-life context. Since the reality of disasters is that they are complex systemic phenomena or 'wicked problems' (Tatham and Houghton, 2011), a case study is an appropriate research approach to use when exploring and attempting to make sense of this complexity (Yin, 2003; Flyvbjerg, 2006). This paper is based on a single case study, namely the 2011-2012 Somali food crisis. The selection of this case is information-orientated (Flyvbjerg, 2006) and reflects the fact that this particular event (or series of events) is an extremely complex disaster (WFP, 2011) and will, therefore, be instructive and generate a large variety of logistics situations and operational challenges.

The source of evidence used in the case study is secondary documentation and draws, in particular, on the relevant operational reports of the UN Logistics Cluster. According to Yin (2003), such documentary information is a valid source of evidence in case study research as long as the 
documents are accurate and not biased. Clearly, this can be an issue if the documents used have not been written for the purpose of the case study, but rather for another use or a different audience.

The Logistics Cluster is a UN coordination mechanism whose objective is to coordinate the relief logistics activities of UN agencies and other humanitarian organisations. To that end, and in order to support field operations, the Logistics Cluster concentrates logistics expertise, facilitates interactions, and disseminates accurate, timely, and quality information to the humanitarian community (Logistics Cluster, 2013a). Given their operational orientation, the validity of the Logistics Cluster's documentary sources can be assumed for the purpose of identifying the various logistics challenges and implications of a disaster.

Table 1 shows the 79 reports reviewed. These were selected from the totality of reports available on the Logistics Cluster website (Logistics Cluster, 2013b) on the basis of their incorporation of specific logistics information.

Table 1: Documentary sources used for the case study

\section{[INSERT TABLE 1 ABOUT HERE]}

Further information regarding the methodological approach to the case study will be provided later in the paper after the details of the model (i.e. the details of the analysis framework) have been discussed.

\section{Conceptual framework}

\subsection{The construction of typologies}

A typology is defined as a 'multidimensional classification', in other words, 'a grouping of entities on the basis of similarity' (Bailey, 2000, p. 3180). Some authors (such as Doty and Glick, 1994) make a distinction between a classification and a typology. However, given that these terms are used interchangeably within the social sciences literature (Bailey, 2000), this approach will also be used in this paper.

Various authors provide guidance as to what constitutes a good classification. Thus, Sandri (1969) argues that, since a series of data can be classified along various dimensions, the rationale for choosing meaningful dimensions is important when building any classification model. Ultimately, as Bailey (1994) observes, a classification is as good as the dimensions on which it is based, or, put simply, pointless dimensions produce pointless classifications. Further crucial elements are exhaustivity (all the entities to be classified belong to one cell type) and mutual exclusivity (the entities cannot belong to two different cell types) (Tiryakian, 1968; Bailey, 1994). According to McKinney (1969), good typologies are functional, in the sense that they contribute to the analysis and prediction of the studied phenomena. Similarly, Sandri (1969) argues that the chosen dimensions must be empirically relevant to enable researchers to derive valid explanations and predictions. For Bailey (1994), good typologies are versatile. This means that they are not only based 
on conceptual considerations, but can also be used to conduct empirical investigations. These discussions show that the empirical verification of the types identified by the classification process is crucial (McKinney, 1966) and this approach is operationalised through the case study later in this paper.

Typologies have been criticised by a number of authors for being simplistic and unsophisticated (Collier et al., 2012). It is accepted that any phenomenon is a unique occurrence in space and time so that typologies are, to some extent, generalisations that cannot capture the whole diversity and complexity (McKinney, 1966; Tiryakian, 1968; McKinney, 1969; Bailey, 2000). They are also constructs that stem from the researcher's mind and, as such, may (and probably do) not exactly match the reality. However, it is argued that, provided the empirical approximations are valid, they are a useful means for organisation, conceptualisation, and analysis (Becker, 1940; Bailey, 1994). Indeed, typologies are a helpful descriptive tool (Bailey, 1994) that enables scholars to reduce and make sense of the complexity of a particular phenomenon (McKinney, 1966; Bailey, 1994; Doty and Glick, 1994). They also allow researchers to identify subsets of research (Collier et al., 2012), to focus on an isolated set of characteristics, and to predict the likely outcomes of these circumstances (Becker, 1940).

\subsection{Open systems and the impact of the external environment}

As commonly defined (for example by Ackoff, 1971; Kast and Rosenzweig, 1972; Daellenbach and McNickle, 2005), a system is an integrated whole made of interrelated elements. Whilst systems can be found in many fields of science, the general system theory has a degree of abstraction and generalisation sufficient to be applicable to a large number of disciplines (von Bertalanffy, 1950; Boulding, 1956; von Bertalanffy, 1972). This widespread applicability, as well as the focus of the general system theory on open systems (von Bertalanffy, 1968), make this theoretical concept appealing to the present research because its overall principles can be used to refine the concept of a disaster and to understand it as a system.

A system is said to be open when its behaviour and performance are influenced by its external environment (Ackoff, 1973). A system can also be so integrated into its environment that system and environment become one entity (Luhmann, 1995; Heil and Droege, 2006). This is the case of disasters, as will be evidenced later. As it is not possible to control and predict all the behaviours and intricate influences, open systems have to deal with uncertainty (Thompson, 1967). It is, nevertheless, argued that one should identify, as much as possible, the variables and interactions in order to better understand them and be in a position to reduce the level of uncertainty. Thus, clearly identifying and carefully studying the nature of the external environment is important (Katz and Kahn, 1978) in order to optimise decision-making by achieving better control on known variables and interactions and by better adapting to unknown elements.

In relation to this paper, the open systems theory justifies the inclusion of the external environment in the model that will be presented later. It also provides a dynamic perspective to our analysis, as discussed in the next sub-section. 


\subsection{Linking typologies and systems}

Typologies and systems are highly related concepts. Thus, McKinney (1969) argues that types within a typology do not exist in isolation, but within a specific context. Consequently, types feature both a classification and a systemic perspective. The classification perspective is based on the similarity of constructed attributes, whereas the systemic perspective emphasises interconnectedness and the inclusion of the studied phenomena into an integrated whole. By not considering both these levels of analysis, researchers are at risk of not providing an accurate representation of the reality.

This analysis echoes von Bertalanffy's (1950) view that there are two levels of analysis for any phenomenon. On one hand, the classification level, by picturing patterns, results in a static view of the event. On the other hand, the system level, by focusing on relationships and interactions, leads to a dynamic understanding of the same phenomenon. Similarly, Katz and Kahn (1978) identify two aspects of the system structure: the system's character (the predictable elements of the system) and the system's openness (the continuous interactions between the system and its environment). For the purpose of this paper, both levels of analysis are helpful and will be used in relation to the proposed disaster classification model. However, before doing so, it is important to evaluate the value of the most frequently used typology of disasters in the light of the concepts and criteria that have been previously developed and, thereby, demonstrate its limitations.

\section{Limitations of the currently used typology of disasters}

The humanitarian logistics literature frequently refers to Van Wassenhove's (2006) typology that makes a distinction between slow- and rapid-onset disasters, and between natural and man-made events (Figure 1). Although this typology is a descriptive tool and its author does not propose its use as a logistics-relevant categorisation of disasters, to date, it has been the most commonly used classification of disasters in the humanitarian logistics literature. However, this paper identifies the reasons why, from a logistics perspective, this typology is not optimal for use as an analytical tool.

Figure 1: Categories of disasters (Van Wassenhove, 2006, p. 476)

[INSERT FIGURE 1 ABOUT HERE]

Although this typology is certainly simple and easy to understand, it is suggested that it does not capture the context and complexity of disasters (Kovács and Spens, 2009; Tatham et al., 2013). Importantly in the context of this research, it does not reflect the logistics impact of an event (L'Hermitte et al., 2013; Tatham et al., 2013), nor the contextual variables and their interactions.

Figure 1's typology can be evaluated against two of the criteria previously developed in this paper, namely: (1) exhaustivity/mutual exclusivity and (2) empirical relevance. First, whilst the typology is certainly exhaustive (all disasters can be classified within it), it is not mutually exclusive because some disasters belong to two different types, as exemplified by a flood event (Kovács and Spens, 2009). Indeed, as explained by L'Hermitte et al. (2013), a flood can be categorised as a sudden-onset, 
a slow-onset, a natural, and a man-made disaster. Since a disaster has rarely only one cause (Kovács and Spens, 2009; Day et al., 2012; Starr et al., 2012), it can be extremely difficult to identify its origin (Quarantelli, 1991; Rosenthal, 1998) and, consequently, to attempt to classify it as a natural or a man-made event. From that perspective, the horizontal dimension of the typology presented in Figure 1 (natural vs. man-made disasters) has limitations.

Secondly, the dimensions of the above typology do not reflect the reality of the studied phenomena and, in particular, the logistics implications of disasters. This is due to the fact that no valid predictions can be derived from the dimensions of this typology. As such, the above typology does not form a suitable basis for analysis. For example, it could be intuitively argued that sudden-onset disasters lead to emergency response operations, whereas slow-onset disasters can be more anticipated and, therefore, result in the availability of longer intervention times. In the reality, the speed of onset does not always reflect the time available for planning and preparing the humanitarian intervention. This is because sudden-onset disasters such as earthquakes evolve and become more stable situations in the recovery phase (Altay et al., 2009; Hughes, 2009), whilst emergency situations exist in the context of slow-onset disasters such as famines. In respect of the latter point, Levine et al. (2011), Kim and Guha-Sapir (2012), and Maxwell et al. (2012b) clearly demonstrate that the humanitarian response to (albeit predictable, foreseen, and recurrent) food crises is repeatedly delayed so that aid agencies have to intervene in emergency once extremely dire famine situations have arisen. Thus, the vertical dimension of the typology presented in Figure 1 (sudden- vs. slow-onset disasters) also has clear limitations.

It is suggested that Figure 1's typology reflects what Quarantelli (1991) calls phenotypes (observable physical features), rather than genotypes (common non-observable features). More precisely, the dimensions of this typology reflect neither the underlying logistics features of a disaster (i.e. those common non-physical features from a logistics perspective) nor its operational implications. Rather, as L'Hermitte et al. (2013) argue, the typology presented in Figure 1 is more focused on the trigger events (i.e. the observable physical features) than on their outcomes. Consequently, this typology is based on dimensions that do not reflect the real-life circumstances of the operational response and, from a humanitarian logistics perspective, that do not support valid empirical investigations and, hence, the development of appropriate general disaster management practices.

Emergent discussions in the humanitarian logistics literature (Kovács and Spens, 2009; Tatham, 2009; Apte, 2010; Tatham et al., 2013) argue for an alternative classification based on characteristics that better reflect the operational implications of disasters. Various researchers (Kovács and Tatham, 2009; Apte, 2010; Holguín-Veras et al., 2012) have offered a number of relevant analysis dimensions and disaster characteristics. In our opinion, the most holistic classification framework to date has been proposed by Tatham et al. (2013) who provide an exhaustive list of thirteen disaster characteristics that impact on humanitarian logistics operations:

1. the time available for action,

2. the number of persons affected,

3. the population density of the impacted area,

4. the geographic extent of the impacted area,

5. the magnitude of the destruction,

6. the disaster duration,

7. the urbanisation level of the affected area, 
8. the topography of the impacted area,

9. the climatic conditions,

10. the socio-economic circumstances of the impacted area,

11. the impacted area's Logistics Performance Index,

12. the level of political stability,

13. the probability of the event's historic occurrence and potential recurrence.

However, the work of Tatham et al. (2013) is limited to the identification of the logistics-oriented characteristics and a tentative scale for each of the characteristics outlined above. Whilst these authors do not develop any typology of disasters, their research can be extended by considering the following three dimensions in their analysis: time, space, and situational circumstances, as undertaken by L'Hermitte et al. (2013). These three commonalities are integrated into the building of the new disaster classification model presented in the next section.

\section{A new classification model of disasters}

Building on the above developmental work, the logistics-focused disaster classification model proposes four categories of disasters based on two generic dimensions (time available for action and geographic scope) and integrates five situational factors that reflect the impact of the external environment on the logistics operations. The derivation of this model is explained in the following sub-sections. However, a more detailed discussion about the construction of the model is available in L'Hermitte et al. (2013).

\subsection{Typology of generically defined disasters}

The overall idea behind this new typology is to identify disaster situations based on the logistics impact of the event (rather than on its physical features) and, consequently, to enable researchers and practitioners to differentiate, explain, and predict the disaster's operational context and outcomes. As logistics is about creating time and place value (Ballou, 2004) along the supply chain, and two crucial implications of disasters are when and where humanitarian supplies should be made available (PAHO, 2001), the row and column variables of the new typology are the time and space dimensions of disasters. The time dimension of a disaster is defined as the time available for action (e.g. for the delivery of the humanitarian supplies) (L'Hermitte et al., 2013). Self-evidently, this relates to the level of emergency of the humanitarian operations. The space dimension of a disaster refers to the geographic scope of the affected area (L'Hermitte et al., 2013). Within these two dimensions, the underlying characteristics provide further refinement.

Thus, the space dimension of a disaster is designed to differentiate between localised disaster situations that impact a contained geographic location, and diffuse disaster situations that impact a widespread geographic location (L'Hermitte et al., 2013). Distinguishing localised from diffuse disasters is essential from a logistics perspective because the geographic extent of a disaster influences the complexity of operations, not least the transport and distribution operations (Apte, 2010). Whilst the travel distances are smaller in the case of localised disasters (which facilitates the carrying out of logistics operations), responding to diffuse disasters is complicated by longer transportation distances and times. This leads to more complex and multi-layered distribution networks (Holguín-Veras et al., 2012), sometimes across borders. 
The time dimension of a disaster allows a distinction to be made between those: the emergency disaster situations characterised by a need for urgent action, and the protracted disaster situations characterised by the availability of longer distribution times (L'Hermitte et al., 2013). Ultimately, the time dimension of a disaster is closely related to the stages of the disaster lifecycle. As illustrated by Safran's disaster management cycle (in ADB, 2004), disaster management is an ongoing process involving four phases (disaster occurrence, emergency response, recovery, and prevention) that aim to plan for and respond to a disaster, as well as to reduce its impacts. Obviously, in the framework of this research, it is expected that operations in the initial phases (disaster occurrence and emergency response) are carried out in response to emergency disasters whereas the later phases (recovery and prevention) are related to protracted disasters. Differentiating between emergency and protracted disasters also reflects the types of operations conducted by humanitarian organisations, such as World Food Programme (WFP). Thus, WFP conducts 'Emergency Operations' to provide immediate relief (WFP, 2012a) and 'Protracted Relief and Recovery Operations' to provide longerterm assistance and/or to re-establish livelihoods (WFP, 2012b).

Figure 2 presents the newly created typology of generic disaster situations based on their logistics implications.

Figure 2: Typology of generic disaster situations based on their logistics implications

[INSERT FIGURE 2 ABOUT HERE]

As typologies never exactly match real-life situations, each cell represents a polar type (or a representative extreme opposite type) (Bailey, 1994). In reality, each dimension should be seen as a continuous variable (Collier et al., 2012) so that the four types identified in Figure 2 do not constitute perfectly homogeneous areas (McKinney, 1966). However, it is suggested that they are sufficiently homogeneous to serve as a sound basis for analysing the logistics implications of each type of disaster situation.

This typology represents the first level of the proposed classification model. In doing so, it will be recognised that it represents the predictable and static part of the model, as will be further developed in a later section. Importantly, it is not considered to be sufficiently comprehensive to reflect the reality of a disaster from a logistics perspective. Thus, and as outlined by von Bertalanffy (1950) and by Katz and Kahn (1978), a second level of analysis is needed that will provide a dynamic dimension.

\subsection{External situational factors}

Using the work of Kunz and Reiner (2012), L'Hermitte et al. (2013) identify five external situational factors that need to be considered over and above the characteristics of the disaster itself because they affect the logistics operations and the associated performance of the humanitarian response. These five environmental elements are: 
- the government situational factors,

- the socio-economic situational factors,

- the infrastructure situational factors,

- the physical situational factors,

- the security situational factors.

It should be noted that the term 'environmental' used in Kunz and Reiner (2012) and in L'Hermitte et al. (2013) has been replaced by 'physical' situational factors in this paper to avoid any possibility of confusion with the term 'environment' that is used to refer to the whole external environment (that includes the five situational factors). In addition, the 'conflict' situational factors have been replaced by the more overarching 'security' situational factors as a result of the case study analysis, as will be explained later. The impact of these situational factors on logistics operations has been emphasised in L'Hermitte et al. (2013) and will be considered again later in this paper in relation to the Somali case study.

For now, it is essential to note that the five environmental factors are dynamic in the sense that there are interactions between them, and that they create obstacles and complexities in the logistics operations. In respect of the latter aspect, Katz and Kahn (1978) propose four general dimensions in order to qualify the level of complexity in the external environment: stability-turbulence, diversityhomogeneity, clustering-randomness, and scarcity-munificence. These dimensions can be used to understand the level of complexity generated by the external situational factors in the field of humanitarian logistics, as is now explained.

First, the stability-turbulence dimension relates to the changing nature of the environment (Katz and Kahn, 1978). Turbulences exist in the disaster environment. For example, a conflict environment can create instability (such as a sudden rise in tension or unexpected population movements), as does the government environment (e.g. political instability due to a breakdown of law and order).

Secondly, the diversity-homogeneity dimension refers to the degree of variety or uniformity in the environment and, consequently, to how difficult/easy it is to understand and adapt to it (Katz and Kahn, 1978). Considerable variety is generated by the disaster's external environment, as exemplified by the diversity of physical environments (for example: rural, urban, mountainous), or the large number of actors that humanitarian organisations have to deal with in a conflict environment (Grünewald, 2012). These actors can be rebellious groups, warlords, militias, or guerrilla forces, as well as the military forces of both the affected country and any international participants.

Thirdly, the clustering-randomness dimension relates to the level of organisation/anarchy in the environment and, consequently, to its level of continuity and accessibility (Katz and Kahn, 1978). In humanitarian logistics, randomness and the lack of operational continuity or accessibility are generated, for example, by the infrastructure environment (when the physical or communication infrastructure is inadequate or has been destroyed) or the government environment (e.g. weak governance and/or predatory approaches leading to corruption) (Maxwell et al., 2012a). The security environment is another cause of randomness, for example when a conflict gives rise to ambush and cargo pilferage (and other types of diversion of humanitarian supplies), as well as to violent acts against aid workers (Stoddard et al., 2006; Stoddard et al., 2009). 
Fourthly, the scarcity-munificence dimension refers to the level of resources (natural, technological, skills, etc.) available (Katz and Kahn, 1978). As an example, scarce resources exist in the disaster's socio-economic environment when there is a lack of commercial transporters or any other logistics service providers in the disaster area.

Taken together, these four dimensions determine the level of complexity that humanitarian organisations encounter and have, subsequently, to manage. In short, the external situational factors either facilitate operations or generate disruptions that prevent the flow of humanitarian supplies and, thus, hamper the logistics and supply chain performance (in terms of efficiency and effectiveness). Consequently, it is argued that, from a logistics perspective, a study of disasters cannot dissociate the disaster itself from its external environment. Both are interlocked as demonstrated in Figure 3 that represents the generically defined disasters within their external environment.

Figure 3: A classification model for logistics-relevant disasters

[INSERT FIGURE 3 ABOUT HERE]

We argue that any given disaster can be classified by using the four dimensions of the matrix (emergency/protracted and diffuse/localised) because they reflect the core attributes of disasters. However, it should be noted that a disaster is not expected to be placed in any of the five categories representing the external situational factors. These elements have been added to the model because they greatly impact on operations and on the logistics decisions, and because a disaster is so integrated into its external environment that it is best represented as one entity. Thus, integrating both levels of analysis into a single model is essential as a means of understanding the complexity and dynamism of the reality of a disaster. Furthermore, it should be noted that the five external situational factors do not exist in isolation, but interact with each other. In order to understand this inherent complexity, further explanation regarding the developed model is provided in the next section.

\subsection{Model analysis and discussion}

The first part of the model (the typology of disasters) represents the static and predictable part of the model in the sense that it is not integrated into the external environment and that the operational context can be predicted. In this instance, the term 'predictable' does not refer to the disaster itself. A disaster can be unpredictable (as is, for example, an earthquake), but the operational outcomes of and the response to this disaster can be predicted on the basis of the generic logistics characteristics of a disaster.

Thus, general logistics and supply chain practices and strategies can be considered for each type of generically defined disaster. For example, a strategy of operational efficiency optimisation is likely to be appropriate in the case of localised and protracted disasters. This is because localised disasters facilitate the achievement of economies of scale (Tatham et al., 2010), whilst protracted disasters 
generate a higher level of demand predictability and more regular and repetitive demand patterns (Holguín-Veras et al., 2012).

By contrast, emergency disasters create more erratic logistics conditions because humanitarian organisations have to face the challenges of responding swiftly to emerging demand. Gattorna (2006) argues that organisations can respond to crisis situations by implementing 'fully flexible' supply chains (the extreme level of supply chain agility). He further explains that fully flexible supply chains are appropriate response strategies in the humanitarian context and, in particular, in emergency situations where the highest level of responsiveness (and low price consideration) is needed to meet unpredictable demand.

Supply chain agility is also needed in the case of diffuse disasters because they generate greater uncertainty and complexity (L'Hermitte et al., 2013). Indeed, a diffuse disaster is more likely to be subjected to the influences of the external environment and, therefore, to generate a more complex operational environment (due, for example, to the variety of physical environments humanitarian organisations have to work in, the range of actors they have to deal with, or the different levels of emergency they have to face). Put simply, diffuse disasters are likely to create a greater variety of operational contexts.

Clearly, the above analysis only touches on the suitability of specific supply chain strategies to particular disaster situations and, as will be discussed later in this paper, further research is needed in this area. Nevertheless, it is argued that, as a first step, developing a categorisation of disasters on the basis of their logistics implications will facilitate the development and applicability of general logistics and supply chain practices and strategies that will, in turn, enhance the performance of the supply chain in response to each type of disaster. This approach is in line with the view of HolguínVeras et al. (2012) who note that researchers are prevented from developing relevant analyses and recommendations for improving humanitarian operations by the lack of differentiation between operational environments in humanitarian logistics.

Whilst the first part of the model is based on similarity (of the constructed attributes), the second part reflects the dynamic circumstances of a disaster situation because the external situational factors create uncertainty and a swiftly changing environment in which humanitarian organisations must be able to operate. The external environment is also specific to each disaster. Therefore, it poses particular challenges to humanitarian logisticians (Kovács and Spens, 2009) and accounts for the uniqueness of each particular supply chain conditions (Whybark et al., 2010). From this perspective, it is evident that, like many other organisations, a humanitarian organisation is an open system interacting with its external environment. Therefore, in order to operate efficiently and effectively, humanitarian organisations must manage the disruptions generated by the disaster external environment. In other words, they must reduce uncertainty and/or develop coping mechanisms. To do so, it is argued that humanitarian organisations must build dynamic capabilities that enable them to quickly respond to disruptive events, better deal with unpredictability, and protect operations from external influences.

\section{Applying the new classification model to the 2011-2012 Somali food crisis}

6.1 The 2011-2012 Somali food crisis: background information 
In 2011, more than 13 million people were affected by the drought in the Horn of Africa (Somalia, Kenya, Ethiopia, Djibouti, and Eritrea). Among these, 4 million people in Somalia (about half of the population) were in need of humanitarian assistance (CRS, 2012). On 20 July 2011, the UN declared a state of famine in two regions of the Southern part of Somalia (CRS, 2012) based on indicators measuring food consumption, nutrition, and mortality (Haan et al., 2012). In August and September 2011, famine was declared in four more regions, with three of these reclassified from 'famine' to 'humanitarian emergency' in November 2011. This situation triggered massive population displacements of 2.4 million Somalis. Some of them joined cross-border refugee camps, mainly in Kenya, Yemen, and Ethiopia, whereas others became Internally Displaced Persons (IDPs) within Somalia (CRS, 2012).

Whilst drought (leading to crop failures, livestock deaths, loss of livelihood, and soaring domestic food prices) was the dominant reason for the humanitarian crisis in Somalia, the situation was exacerbated by other factors such as rising international food prices (Somalia is significantly dependent on food imports) (Maxwell and Fitzpatrick, 2012), political instability, lack of authority and policy making, an environment of insecurity due to the insurgence of the rebel Islamist group, Al-Shabaab (CRS, 2012), Al-Shabaab's ban on foreign intervention and aid agencies since 2009 leading to increased livelihood vulnerability (Lautze et al., 2012; Menkhaus, 2012), US counterterrorism laws suspending US food aid deliveries to areas controlled by Al-Shabaab (Menkhaus, 2012), and increasing fuel prices impeding transport and food distribution (CRS, 2012). All these factors explain why Darcy et al. (2012) call the drought crisis in Somalia 'a crisis within a crisis' and, thereby, illustrate the point made previously in this paper regarding the existence of multiple causes leading to a disaster.

Very sophisticated disaster detection systems are available in Somalia (Darcy et al., 2012; Hillbruner and Moloney, 2012). Repeated early warnings regarding the Somali drought, acute malnutrition, and the risk of famine had already been released by the end of 2010, but these did not result in an early humanitarian intervention (neither preventive action nor early relief) to the extent required. Consequently, urgent action had to be taken to deliver emergency supplies mid-2011 (Darcy et al., 2012; Kim and Guha-Sapir, 2012; Lautze et al., 2012) when the food crisis in Somalia had become extremely severe and had already resulted in extensive loss of life (Hillbruner and Moloney, 2012).

It is not our intention to lay the blame on the humanitarian organisations as they, obviously, anticipated the approaching crisis (Oxfam, 2012). What is essential and relevant here is that, after the July 2011 famine declaration, the Somali famine (albeit a typical slow-onset disaster) was treated as any sudden-onset emergency (Hobbs et al., 2012). Thus, due to the need for urgent action and for immediate distribution of humanitarian supplies, the Somali disaster is categorised as an 'emergency disaster situation' (in reference to the proposed classification model presented in Figure 3). It should be noted that the level of emergency not only reflects the famine itself, but also its dynamic effects: overcrowded and inadequate refugee camps leading to multiple health issues, security problems such as robbery and sexual violence, and rising tensions between communities (OCHA, 2011).

Although the famine was mainly located in the South-Central part of Somalia, most of the Somali territory was affected by either humanitarian emergency or acute food and livelihood crisis (Maxwell et al., 2012b). The affected populations were diverse and included people living in pastoralist and agro-pastoralist communities, urban areas, IDP settlements, and cross-border refugee camps (FSNAU, 2011). As a consequence, and in reference to the proposed classification model presented 
in Figure 3, the Somali food crisis is categorised as a 'diffuse disaster'. Further detail regarding the logistics implications of this classification will be provided in a later section.

\subsection{Methodological approach to the case study research}

This case study is designed to identify the logistics-oriented characteristics and implications of the 2011-2012 Somali food crisis. In doing so, this paper aims to demonstrate that the proposed classification model offers a route to comprehend the complexity of this particular disaster and, consequently, that the model can be used to conduct empirical investigations.

To do so, the documentary sources presented earlier in Table 1 were reviewed with the aim of understanding how the various variables of the proposed model impact on the logistics operations. To that end, a seven-dimensional framework was used to analyse the documents and identify the operational implications. This framework is based on the dimensions integrated into the classification model presented in Figure 3 and, therefore, includes the following:

- the logistics characteristics of the studied disaster (the time and space dimensions of the model, i.e. emergency and diffuse in this particular case),

- the five external situational factors.

For the purpose of possibly refining the model, the authors have also listed the elements that do not fit any category of the model but that should, nevertheless, be taken into account due to their impact on the logistics activities. Thus, the objectives of this study are twofold:

- to ascertain the appropriateness of the model categories to approach disasters from a logistics perspective,

- to describe the impact of the broader environment on logistics operations and, thus, to demonstrate the relevance of a two-level classification framework.

A map of Somalia showing the administrative regions as well as the ports is provided in Figure 4 to enhance the understanding of the case study analysis. As some readers may need more extensive mapping information, a more detailed map is available on the Logistics Cluster website (Logistics Cluster, 2011).

Figure 4: Administrative map of Somalia (OCFA, 2011, p. 3)

[INSERT FIGURE 4 ABOUT HERE]

\subsection{The space and time characteristics of the 2011-2012 Somali food crisis}

The case study illustrates the space and time dimensions of the model and, in particular, provides valuable information regarding the logistics challenges associated with (1) a diffuse and (2) an emergency disaster situation. What follows is, thus, an analysis of the specific set of characteristics distinguishing this particular type of disaster (diffuse and emergency). 
Several logistics implications relating to the diffuse characteristic of the Somali disaster demonstrate the higher level of complexity associated with diffuse disasters. First, the case study shows that a diffuse disaster situation results in a heterogeneous operational environment to which humanitarian organisations have to adapt. This not only relates to the variety of intervention environments (urban, rural, or refugee camps), but also to the diversity of operational practices. For example, different ports have different berthing rules and priorities. Secondly, the widespread geographic scope of the studied disaster results in the movement of humanitarian supplies through various land corridors and over large distances. Thirdly, the documents report a number of cross-border logistics challenges. These include the remote management of the crisis (with humanitarian organisations operating out of Kenya due to security issues) bringing about inadequate logistics coordination, the lack of port capacity resulting in humanitarian organisations using overseas ports (so that congestion at Mombasa Port in Kenya affects the deliveries to the Somali population), or the cross-border refugee movements that complicate logistics planning and operations. Population movements lead to new logistics requirements such as remapping the refugee locations, additional need for food supplies and non-food humanitarian items (such as shelters and health kits), and increased storage requirements in refugee camps. This issue of population displacement shows that a diffuse disaster can evolve in space.

In addition to the space dimension, the time dimension (i.e. emergency disaster requiring immediate assistance) is also reflected in the case study. First, the need for urgent action is particularly clear at the first stage of the disaster, as illustrated by the need to deliver essential items (such as food or medicines) rapidly, and the resultant use of air transport (before deliveries by road can be arranged). Then, the case study demonstrates that new emergencies can develop at any moment, such as in March 2012, when refugees (mainly from Kenya) returned to the Hiiran and Bay regions (SouthCentral Somalia) in great numbers in part following Al-Shabaab's withdrawal from many towns. Humanitarian organisations had to swiftly identify immediate needs, target populations, and accordingly adapt their response strategy.

The documents also refer to the uncertainty typically associated with an emergency disaster situation. For example, they reveal that humanitarian organisations lack basic information, in particular at the start of the disaster event. This lack of information relates, among other issues, to transport rates, mechanisms to transport cargo out of the port of entry to destinations within Somalia, and mapping details. Finally, the emergency characteristic of the disaster is reflected in the fact that logistics activities are not fully operational at the beginning of the disaster period and, consequently, in the need to set up the operational framework, i.e. to establish humanitarian pipelines such as land corridors or airstrips.

The 2011-2012 Somali disaster shows that the level of emergency of a disaster can evolve over time. Thus, in February 2012, improvements in food security and the reduction in mortality levels brought the two main organisations in charge of food security surveillance (FSNAU and FEWS NET, 2012) to announce the end of the Somali famine. Clearly, this does not mean that humanitarian assistance is no longer needed, but that the level of the emergency has evolved. Thus, the categorisation has changed and the Somali disaster has evolved from an emergency disaster to a protracted disaster. In this respect, it will be seen that, from 2012, humanitarian organisations have moved from emergency life-saving to recovery assistance and, consequently, have been conducting protracted operations in Somalia (WFP, 2012c). 
In summary to this section, the case study describes the operational environment of a diffuse and emergency disaster and confirms that these events generate such a degree of operational uncertainty and complexity that the response strategy of humanitarian organisations must be totally focused on responsiveness and flexibility. Clearly, as will be discussed later, this point has to be more deeply investigated. The case study also demonstrates that disasters evolve and move from an emergency situation to a protracted situation in the recovery phase.

\subsection{The external situational factors of the 2011-2012 Somali food crisis}

The case study illustrates the five external situational factors of the disaster classification model presented in Figure 3. Each of them is now considered.

The impact of the infrastructure environment on the logistics operations is repeatedly referred to, in particular due to the lack of port capacity. This leads to recurring congestion issues at the various ports used as points of entry for the deliveries of relief items to Somalia (Dar Es Salaam in Tanzania, Mombasa in Kenya, Mogadishu, Bossaso, and Berbera in Somalia, as well as Djibouti). Congestion results in delays in berthing (sometimes reaching 20 days, such as at Mombasa Port's bulk terminal in December 2011) and in cargo handling. In addition to overstretched port capacity, the reviewed documentation mentions as an infrastructure issue the inadequacy of the design of Mombasa Port where too few gates are used by a large number of vehicles.

The impact of the physical environment is also widely reported in the case study documents. Poor weather conditions lead to multiple logistics disruptions, including delays in loading and discharging vessels (compounding berthing delays), and to the deterioration of road conditions resulting in operational delays on supply routes (because some muddy or flooded roads are impassable or, when passable, vehicles must move slowly). This, in turn, slows down the turn-around time of trucks causing a shortage of trucking capacity and, therefore, further delays in the deliveries of humanitarian supplies. Poor weather conditions not only impede truck movements, but also result in the inability to use certain airstrips. In addition, heavy rains and flooding bring about further population movements (due to property destruction, crops being damaged, and the death of domestic animals) and also impact on the logistics operations in camps. For example, rainy conditions increase the need for shelter items or health kits (to prevent the risk of acute watery diarrhoea or the spread of diseases such as cholera, measles, and malaria).

The case study demonstrates how a range of socio-economic factors affects logistics operations. In particular, the reviewed documentation shows that logistics challenges are brought about by the lack of available resources and labour issues. The lack of resources includes shortfalls in storage capacity in Mogadishu and other locations in Somalia (resulting in higher storage prices), and the shortage of trucking capacity in Mombasa, Djibouti, Dar Es Salaam, and Bossaso (causing delays in discharging cargo and in transporting humanitarian supplies ex-port). The insufficient road transport capacity is compounded by the competition between humanitarian and commercial cargo. Thus, some transporters prefer to carry commercial cargo because the turn-around times are quicker, the routes are more lucrative, and several commercial actors have agreed to pay in advance for the transport services. The shortages of available resources also relate to the absence of regular and reliable sea transport services (between the various ports within Somalia as well as between 
Mombasa and Mogadishu/other Somali ports) and air transport services (for cargo and passengers, i.e. the humanitarian personnel). The air operations are further impacted by the lack of fuel at Mogadishu airport in August 2011 that resulted in an increase in the cost of airlifts and the need to adapt operations by refuelling in Kenya. Finally, socio-economic factors include an ongoing labour shortage at Mombasa Port and the consequent labour disputes (between the dock workers' union and the Port Authority) that resulted in further delays in the loading and discharge of vessels.

A number of government situational factors and the related logistics issues are referred to in the case study reports. These include, for example, slow customs procedures that delay cargo movements. Likewise, a decision of the Puntland (North-Eastern Somalia) authorities not to allow large convoys (i.e. more than ten trucks per convoy) to cross the border from Somaliland (Northern Somalia) into Puntland greatly affected the humanitarian logistics activities. Separate clearance was required for each convoy and this led to the spreading out of the deliveries over longer periods of time and, consequently, to distribution delays. Another example of government factors impacting on logistics operations relates to an administrative decision designed to reduce congestion at Mombasa Port. According to the new rules, the time that transit containerised cargo could remain at the terminal before incurring storage charges was reduced from 11 to 9 days. This decision directly impacted on the already insufficient trucking capacity and the difficulty encountered by humanitarian organisations in finding transporters to carry relief items ex-port.

The case study also shows how the conflict environment impacts on the logistics operations, in particular as a result of the related security issues. These bring about massive population displacements, increased transport rates, coordination difficulties and, in turn, clearly affect the planning of operations and cargo movements. Other conflict environmental factors impeding the delivery of humanitarian supplies include mine threats and, most importantly, access-related restrictions. These are due, for example, to border closings or to Al-Shabaab's ban on humanitarian agencies from working in South-Central Somalia.

The documentary analysis reports the particular issue of maritime piracy that occurs in the Horn of Africa and results in the need to arrange for the vessels to have a naval escort. Undoubtedly, piracy is embedded into Somalia's broader political/conflict and socio-economic environments (Dua and Menkhaus, 2012). However, the piracy issue and the resulting security and logistics implications (Sullivan, 2010) do not seem to totally fit into the model as presented in L'Hermitte et al. (2013). Therefore, the 'conflict' situational factors have been renamed and a more overarching term used, namely 'security' environmental factors.

In addition to illustrating the five external situational factors, the documentary analysis shows the intricate interconnections between them. Thus, a number of logistics challenges are due to a combination of various factors. For example, the causes of heavy congestion at Mombasa Port (and the resultant delays) are the insufficient port capacity to meet the commercial and humanitarian demand (infrastructure variable), labour disputes between the dock workers' union and the Port Authority due to ongoing labour shortages (socio-economic variable), and rainfalls (physical variable) impeding port operations and reducing the trucks' turn-around time, which, in turn, increases the shortage of trucks. The complex and entangled disaster external environment is also dynamic, in the sense that a logistics-relevant force can trigger a series of other logistics-related after-effects. For example, the administrative decisions made to reduce port congestion in Mombasa further impacts 
on the shortage of trucking capacity. This confirms the relevance of the systemic approach taken in this paper.

Finally, the study of the 2011-2012 Somali food crisis shows that the disaster environment is constantly changing. Changes concern all five environmental variables, for example: changing weather conditions (physical variable), fluctuating port congestion (infrastructure variable), changing trucking capacity (socio-economic variable), evolving administrative decisions (government variable), and security issues changing the level of accessibility to certain locations (security variable).

To conclude this section, the evidence in the case study strongly supports the use of the four dimensional conceptualisation of the external environment (stability-turbulence, diversityhomogeneity, clustering-randomness, and scarcity-munificence) developed by Katz and Kahn (1978) in order to qualify the level of complexity in the external environment. In the case of the 2011-2012 Somali food crisis, the disaster environment is highly turbulent (it is ever-evolving), diverse (the degree of variety is high), random (the level of continuity and accessibility is low), and scarce (the resources available are insufficient). It is, consequently, a very complex environment that generates numerous logistics challenges and impedes the delivery of humanitarian supplies to those in need. In addition, the case study shows that humanitarian organisations have very little (if no) influence on the broader external environment. Thus, they have to be responsive and flexible enough to adapt the complex and dynamic circumstances created by the external factors.

\section{Research value and conclusions}

This paper is a step towards an improved differentiation and categorisation of disasters in humanitarian logistics. By identifying common characteristics driving logistics needs, it highlights the existence of disaster situations (based on their logistics implications) as opposed to just disasters (based on their physical characteristics). As humanitarian logistics decisions are contingent upon the operational context, the identification of generic types of disasters is a first step towards the categorisation of logistics and supply chain practices and strategies associated with each type of disasters. Thus, the new typology will provide more structure to the humanitarian logistics discipline, help researchers to better differentiate the logistics environments, and will facilitate analysis. In particular, it will emphasise new research opportunities beyond emergency disasters that represent, to date, the main academic focus (Kunz and Reiner, 2012).

The literature review conducted and the case study analysis further demonstrate that logisticsrelevant disasters cannot be categorised by only considering the common attributes of the disaster itself (emergency/protracted and diffuse/localised). This is not sufficient to reflect the reality of the logistics conditions. A holistic approach is necessary because humanitarian organisations operate in a highly complex and dynamic external environment that constantly disrupts the flows of supplies. As illustrated by the case study, disruptions include access limitations, capacity constraints bottlenecks, and security issues. Thus, the study of disasters and of the logistics operations in response to them must include the impact of the disaster's broader environment. As the exogenous factors making up this environment are intricate and beyond the control of humanitarian actors, organisations need to be flexible and responsive enough to adapt to the disruptive events. It is argued that the operational performance of humanitarian organisations is contingent upon their 
ability to build agile capabilities to swiftly respond to external disruptions and to conduct dynamic operations. In other words, operational performance depends on their ability to protect operations from external events.

In summary, although the contribution of this paper is primarily conceptual, it is argued that an improved differentiation between the disaster environments will assist researchers in focussing more on the drivers of logistics performance with consequential longer term benefits to practitioners.

\section{Limitations and further areas of research}

This paper forms the foundations of an ongoing study regarding supply chain disruptions and the drivers of performance in humanitarian logistics. At this stage, this work intends to clarify the concept of a disaster from a logistics perspective and to provide a new academic framework in order to make sense of the disaster situations. The proposed model should not be seen as definitive, but rather as a first reflection regarding the categorisation of disasters based on their logistics implications. In particular, as the paper is based on a single case study, the findings related to the validity of the proposed classification model must be understood in the context of the 2011-2012 Somali food crisis. It follows that, notwithstanding the illustrative case study used in this paper, further research is needed to test the model against further real-life circumstances and, in particular, a broader selection of disaster situations. This will provide new opportunities to refine the proposed classification.

In addition, since the paper is based on secondary data, the validity and utility of the new classification model need to be tested with practitioners so that its value as a decision-making tool can be better understood. In order to improve decision-making, further research is also needed to investigate the operational characteristics of each disaster type and the suitability of specific logistics and supply chain practices and strategies in response to particular disaster situations. Similarly, additional investigations should focus on the impact of the external environment on the logistics operations. Whilst this paper shows that the disaster broader environment generates disruptions, it does not provide any details regarding the way to reduce uncertainty and achieve responsiveness and flexibility in order to overcome these disruptions and operate more efficiently and effectively. Consequently, a more detailed and scientific analysis of the interactions between a disaster and the humanitarian response is still needed. In particular, it should be understood how the knowledge about a disaster, its environment, and its logistics implications guides decision-making and action in the field.

\section{Summary}

This paper uses insights from theories, existing academic research, and empirical evidence to propose a new classification model for disasters based on their logistics implications. The theorybased approach uses the literature relating to the construction of typologies and to open systems in order to explain the development of the two-level classification model. This model shows that the nature of the humanitarian logistics operations is determined by the generic characteristics of the 
disaster itself and the external situational factors. It is argued that the disaster's generic characteristics enable researchers to predict the operational context, whereas the external environment creates uniqueness as well as uncertainty that interrupts the flow of humanitarian supplies. Consequently, this paper studies a disaster as a system. Understanding the system forces and interactions contributes to increased control, reduced uncertainty, and improved decisionmaking.

The case study confirms the validity of this systemic approach by demonstrating that, from a logistics perspective, a disaster is a highly intricate phenomenon made of interconnected elements and entrenched in its external environment. Consequently, a full analysis of the logistics implications of a disaster can only be achieved through the understanding of the influences of the external environment. As the environmental forces create numerous disruptions and account for the level of operational complexity that humanitarian organisations have to face, defining a disaster from a logistics perspective is only possible by integrating the disaster into its broader context and considering it in its complexity. Even in a disaster situation as intricate as the 2011-2012 Somali food crisis, a methodical analysis of the multiple variables has proved to be useful to make sense of the disaster complexity. This provides an initial validation of the conceptual approach.

\section{References}

Ackoff, R.L. (1971), "Towards a System of Systems Concepts", Management Science, Vol. 17, No. 11, pp. 66171.

Ackoff, R.L. (1973), "Science in the systems age: beyond IE, OR, and MS", Operations Research, Vol. 21, No. 3, pp. 661-71.

ADB (2004), Disaster and emergency assistance policy, Asian Development Bank, available at: http://www.adb.org/documents/disaster-and-emergency-assistance-policy (accessed 11 October 2013).

Altay, N., Prasad, S. and Sounderpandian, J. (2009), "Strategic planning for disaster relief logistics: lessons from supply chain management", International Journal of Services Sciences, Vol. 2, No. 2, pp. 142-61.

Apte, A. (2010), Humanitarian logistics: a new field of research and action, Now Publishers, Hanover, MA.

Bailey, K.D. (1994), Typologies and taxonomies: an introduction to classification techniques, Sage Publications, Thousand Oaks, CA.

Bailey, K.D. (2000), "Typologies", in Borgatta, E.F. and Montgomery, R.J.V. (Eds.), Encyclopedia of sociology, Macmillan Reference, New York, NY, pp. 3180-9.

Ballou, R.H. (2004), Business Logistics/Supply Chain Management, Pearson Education, Upper Saddle River, NJ.

Becker, H. (1940), "Constructive typology in the social sciences", American Sociological Review, Vol. 5, No. 1, pp. $40-55$

Boulding, K.E. (1956), "General systems theory - The skeleton of science", Management Science, Vol. 2, No. 3, pp. 197-208.

Collier, D., LaPorte, J. and Seawright, J. (2012), "Putting typologies to work: concept formation, measurement, and analytic rigor", Political Research Quarterly, Vol. 65, No. 1, pp. 217-32.

CRS (2012), Horn of Africa: the humanitarian crisis and international response, Congressional Research Service, Washington, DC, available at: http://www.fas.org/sgp/crs/row/R42046. pdf (accessed 21 May 2013).

Daellenbach, H.G. and McNickle, D.C. (2005), Management science: decision making through systems thinking, Palgrave Macmillan, New York, NY.

Darcy, J., Bonard, P. and Shukria, D. (2012), IASC real-time evaluation of the humanitarian response to the Horn of Africa drought crisis - Somalia 2011-2012, Inter-Agency Standing Committee, available at: https://ochanet.unocha.org/p/Documents/IASC-RTE\%20Somalia\%202012.pdf (accessed 23 May 2013).

Day, J.M., Melnyk, S.A., Larson, P.D., Davis, E.W. and Whybark, D.C. (2012), "Humanitarian and disaster relief supply chains: a matter of life and death", Journal of Supply Chain Management, Vol. 48, No. 2, pp. 2136. 
Doty, D.H. and Glick, W.H. (1994), "Typologies as a unique form of theory building: toward improved understanding and modeling", Academy of Management Review, Vol. 19, No. 2, pp. 230-51.

Dua, J. and Menkhaus, K. (2012), "The context of contemporary piracy - The case of Somalia", Journal of International Criminal Justice, Vol. 10, No. 4, pp. 1478-387.

Eshghi, K. and Larson, R.C. (2008), "Disasters: lessons from the past 105 years", Disaster Prevention and Management, Vol. 17, No. 1, pp. 62-82.

Flyvbjerg, B. (2006), "Five misunderstandings about case-study research", Qualitative Inquiry, Vol. 12, No. 2, pp. 219-45.

FSNAU (2011), Nutrition Analysis Post Gu 2011, Food Security and Nutrition Analysis Unit - Somalia, available at: http://reliefweb.int/report/somalia/fsnau-technical-series-report-no-vi-41-nutrition-analysis-postgu-2011 (accessed 27 May 2013).

FSNAU and FEWS NET (2012), Famine ends, yet 31\% of the population remain in crisis, Food Security and Nutrition Analysis Unit and Famine Early Warning Systems Network, available at: http://reliefweb.int/sites/reliefweb.int/files/resources/Full\%20Report 532.pdf (accessed 4 June 2013).

Gattorna, J. (2006), Living supply chains, Pearson Education, Harlow.

Grünewald, F. (2012), "Aid in a city at war: the case of Mogadishu, Somalia", Disasters, Vol. 36, pp. S105-25.

Haan, N., Devereux, S. and Maxwell, D. (2012), "Global implications of Somalia 2011 for famine prevention, mitigation and response", Global Food Security, Vol. 1, No. 1, pp. 74-9.

Heil, K. and Droege, S.B. (2006), "Open and closed systems", in Helms, M.M. (Ed.), Encyclopedia of management, Cengage Gale, Farmington Hills, MI, pp. 596-8.

Hillbruner, C. and Moloney, G. (2012), "When early warning is not enough-Lessons learned from the 2011 Somalia famine", Global Food Security, Vol. 1, No. 1, pp. 20-8.

Hobbs, C., Gordon, M. and Bogart, B. (2012), "When business is not as usual: decision-making and the humanitarian response to the famine in South Central Somalia", Global Food Security, Vol. 1, No. 1, pp. 50-6.

Holguín-Veras, J., Jaller, M., Van Wassenhove, L.N., Pérez, N. and Wachtendorf, T. (2012), "On the unique features of post-disaster humanitarian logistics", Journal of Operations Management, Vol. 30, No. 7, pp. 494-506.

Hughes, K. (2009), "The evolution of fully flexible supply chains", in Gattorna, J. (Ed.), Dynamic supply chain alignment, Gower Publishing Limited, Farnham, pp. 85-95.

HUMLOG (2014), "HUMLOG bibliography", Hanken School of Economics, available at: http://www.hanken.fi/public/en/humlogbibliography (accessed 17 February 2014).

Kast, F.E. and Rosenzweig, J.E. (1972), "General systems theory: applications for organization and management", Academy of Management Journal, Vol. 15, No. 4, pp. 447-65.

Katz, D. and Kahn, R.L. (1978), The social psychology of organizations, John Wiley \& Sons, Hoboken, NJ.

Kim, J.J. and Guha-Sapir, D. (2012), "Famines in Africa: is early warning early enough?", Global Health Action, Vol. 5, pp. 1-3.

Kovács, G. and Spens, K. (2009), "Identifying challenges in humanitarian logistics", International Journal of Physical Distribution \& Logistics Management, Vol. 39, No. 6, pp. 506-28.

Kovács, G. and Tatham, P.H. (2009), "Responding to disruptions in the supply network - From dormant to action", Journal of Business Logistics, Vol. 30, No. 2, pp. 215-29.

Kunz, N. and Reiner, G. (2012), "A meta-analysis of humanitarian logistics research", Journal of Humanitarian Logistics and Supply Chain Management, Vol. 2, No. 2, pp. 116-47.

L'Hermitte, C., Bowles, M. and Tatham, P.H. (2013), "A new classification model of disasters based on their logistics implications", in Lane, R. and Kahn, D. (Eds.), 11th ANZAM Operations, Supply Chain and Services Management Symposium, Brisbane, Australia, 20-21 June 2013.

Lautze, S., Bell, W., Alinovi, L. and Russo, L. (2012), "Early warning, late response (again): the 2011 famine in Somalia", Global Food Security, Vol. 1, No. 1, pp. 43-9.

Levine, S., Crosskey, A. and Abdinoor, M. (2011), System failure? Revisiting the problems of timely response to crises in the Horn of Africa, Humanitarian Policy Group and Overseas Development Institute, London, available at: http://www.odihpn.org/hpn-resources/network-papers/system-failure-revisiting-theproblems-of-timely-response-to-crises-in-the-horn-of-africa (accessed 13 May 2013).

Logistics Cluster (2011), "Horn of Africa - Logistics infrastructures and food insecurity areas", available at: http://www.logcluster.org/ops/som11a/horn-of-africa-logistics-infrastructures-and-food-insecurityareas (accessed 3 June 2013).

Logistics Cluster (2013a), "About the Logistics Cluster", available at: http://www.logcluster.org/about/logisticscluster (accessed 16 May 2013). 
Logistics Cluster (2013b), "Somalia", available at: http://www.logcluster.org/ops/som11a (accessed 15 May 2013).

Luhmann, N. (1995), Social systems, Standford University Press, Standford, CA.

Maxwell, D., Bailey, S., Harvey, P., Walker, P., Sharbatke-Church, C. and Savage, K. (2012a), "Preventing corruption in humanitarian assistance: perceptions, gaps and challenges", Disasters, Vol. 36, No. 1, pp. 140-60.

Maxwell, D. and Fitzpatrick, M. (2012), "The 2011 Somalia famine: context, causes, and complications", Global Food Security, Vol. 1, No. 1, pp. 5-12.

Maxwell, D., Haan, N., Gelsdorf, K. and Dawe, D. (2012b), "The 2011-12 famine in Somalia: introduction to the special edition", Global Food Security, Vol. 1, No. 1, pp. 1-4.

McKinney, J.C. (1966), Constructive typology and social theory, Meredith Publishing Company, New York, NY.

McKinney, J.C. (1969), "Typification, typologies, and sociological theory", Social Forces, Vol. 48, No. 1, pp. 1-12.

Menkhaus, K. (2012), "No access: critical bottlenecks in the 2011 Somali famine", Global Food Security, Vol. 1, No. 1, pp. 29-35.

OCFA (2011), Humanitarian country profile - Somalia, Office for the Coordination of Foreign Aid, Abu Dhabi, United Arab Emirates, available at: http://ocfa.gov.ae/CountryProfiles/Somalia\%20Humanitarian\%20Country\%20Profiles\%201st\%20Edition English.pdf (accessed 7 June 2013).

OCHA (2011), Humanitarian requirements for the Horn of Africa drought, United Nations Office for the Coordination of Humanitarian Affairs, New York, NY, available at: https://docs.unocha.org/sites/dms/CAP/HRD 2011 Horn of Africa SCREEN.pdf (accessed 21 May 2013).

Oxfam (2012), Food crisis in the Horn of Africa, Oxfam International, Oxford, available at: http://www.oxfam.org/sites/www.oxfam.org/files/er-horn-of-africa-2011-2012-progress-report050712-en.pdf (accessed 4 June 2013).

PAHO (2001), Humanitarian supply management in logistics in the health sector, Pan American Health Organization and World Health Organization, Washington, DC, USA, available at: http://www.paho.org/english/ped/HumanitarianSupply.pdf (accessed 17 February 2014).

Pettit, S. and Beresford, A. (2009), "Critical success factors in the context of humanitarian aid supply chains", International Journal of Physical Distribution \& Logistics Management, Vol. 39, No. 6, pp. 450-68.

Quarantelli, E.L. (1991), "Disaster response: generic or agent-specific?", in Kreimer, A. and Munasinghe, M. (Eds.), Managing natural disasters and the environment, The World Bank, Washington, DC, pp. 97-105.

Rosenthal, U. (1998), "Future disasters, future definitions", in Quarantelli, E.L. (Ed.), What is a disaster? Perspectives on the question, Routledge, London, pp. 146-59.

Sandri, G. (1969), "On the logic of classification", Quality and Quantity, Vol. 3, No. 1-2, pp. 80-124.

Shaluf, I.M. (2007), "Disaster types", Disaster Prevention and Management, Vol. 16, No. 5, pp. 704-17.

Starr, M.K., Van Wassenhove, L.N., Apte, A., Goncalves, P., Gupta, S. and Yadav, P. (2012), "Special issue of production and operations management: humanitarian operations and crisis management", Production and Operations Management, Vol. 21, No. 1, pp. 209-10.

Stoddard, A., Harmer, A. and DiDomenico, V. (2009), Providing aid in insecure environments: 2009 update, Overseas Development Institute and Humanitarian Policy Group, London, available at: http://www.odi.org.uk/sites/odi.org.uk/files/odi-assets/publications-opinion-files/4243.pdf (accessed 27 May 2013).

Stoddard, A., Harmer, A. and Haver, K. (2006), Providing aid in insecure environment: trends in policy and operations, Overseas Development Institute and Humanitarian Policy Group, London, available at: http://www.odi.org.uk/sites/odi.org.uk/files/odi-assets/publications-opinion-files/269.pdf (accessed 27 May 2013).

Sullivan, A.K. (2010), "Piracy in the Horn of Africa and its effects on the global supply chain", Journal of Transportation Security, Vol. 3, No. 4, pp. 231-43.

Tatham, P.H. (2009), "The logistic implications of rapid and not-so-rapid onset disasters", 2nd International Humanitarian Logistic Symposium, Faringdon, UK, 25-26 March 2009.

Tatham, P.H., Haavisto, I., Kovács, G., Beresford, A. and Pettit, S. (2010), "The logistic cost drivers of disaster relief", in Whiteing, T. (Ed.), 15th Logistics Research Network (LRN) Conference, Leeds, UK, 8-10 September 2010.

Tatham, P.H. and Houghton, L. (2011), "The wicked problem of humanitarian logistics and disaster relief aid", Journal of Humanitarian Logistics and Supply Chain Management, Vol. 1, No. 1, pp. 15-31. 
Tatham, P.H., L'Hermitte, C., Spens, K. and Kovács, G. (2013), "Humanitarian logistics: development of an improved classification framework", in Lane, R. and Kahn, D. (Eds.), 11th ANZAM Operations, Supply Chain and Services Management Symposium, Brisbane, Australia, 20-21 June 2013.

Thompson, J.D. (1967), Organizations in action: social science bases of administrative theory, McGraw-Hill, New York, NY.

Tiryakian, E.A. (1968), "Typologies", in Sills, D.L. (Ed.), International Encyclopedia of the social sciences, Crowell Collier and Macmillan, New York, NY, pp. 177-86.

UNISDR (2007), "Terminology", United Nations International Strategy for Disaster Reduction, available at: http://www.unisdr.org/we/inform/terminology (accessed 14 January 2013).

Van Wassenhove, L.N. (2006), "Humanitarian aid logistics: supply chain management in high gear", The Journal of the Operational Research Society, Vol. 57, No. 5, pp. 475-89.

von Bertalanffy, L. (1950), "An outline of general system theory", The British Journal for the Philosophy of Science, Vol. 1, No. 2, pp. 134-65.

von Bertalanffy, L. (1968), General system theory: foundations, development, applications, Penguin Books, Hardmondsworth.

von Bertalanffy, L. (1972), "The history and status of general systems theory", Academy of Management Journal, Vol. 15, No. 4, pp. 407-26.

WFP (2011), Somalia Emergency Operation 200281, World Food Programme, available at: http://one.wfp.org/operations/current operations/project docs/200281.pdf (accessed 21 May 2013).

WFP (2012a), "Emergency Operations (EMOPs)", World Food Programme, available at: http://www.wfp.org/operations/emergency (accessed 21 May 2013).

WFP (2012b), "Protracted Relief and Recovery (PRROs)", World Food Programme, available at: http://www.wfp.org/operations/relief (accessed 21 May 2013).

WFP (2012c), Protracted relief and recovery operations - Somalia 200443, World Food Programme, available at: http://one.wfp.org/operations/current operations/project docs/200443.pdf (accessed 4 June 2013).

Whybark, D.C., Melnyk, S.A., Day, J.M. and Davis, E.W. (2010), "Disaster relief supply chain management: new realities, management challenges, emerging opportunities", Decision Line, Vol. 41, No. 3, pp. 4-7.

Yin, R.K. (2003), Case study research: design and methods, Sage Publications, Thousand Oaks, CA. 